\title{
On sterilising severely mentally handicapped people
}

\author{
Raanan Gillon Imperial College of Science and Technology and King's College, London University
}

At the time of writing, the House of Lords in England had not ruled in the case of Jeanette - a seventeen-yearold with allegedly the skills of at most a five or six-yearold whose mother and gynaecologist wished to perform probably irreversible sterilisation by an operation to tie her fallopian tubes (1). Whatever the legal decision, the ethical issues underlying decisions of this kind deserve analysis.

In the normal case the matter is settled by the decision of the woman and her gynaecologist - if she wishes to be sterilised, for example for the purposes of contraception, and a gynaecologist agrees to her request that is the end of the matter so far as the law in England is concerned (2). The underlying ethical argument may presumably be simply but perhaps not inaccurately summarised along the lines that such sterilisation is an operation of sufficient potential benefit and sufficiently small likely harm to be justified if a patient understandingly and autonomously chooses it, and that there are no generally overriding considerations of justice, either in terms of people's rights or in terms of distribution of resources, to prevent such operations.

What changes the ethical argument in the case of a severely mentally handicapped person is of course the absence of sufficient autonomy in the potential patient to make possible her understanding and autonomous choice either to have or not to have the operation. We have developed, however, several apparently justifiable systems for dealing with cases of inadequate autonomy. In general the preferred approach is to try to approximate as closely as possible to what would be the autonomous decision of the person concerned (for instance by reference to earlier expressed autonomous preferences and decisions). That route is blocked however in the case of those people who have never developed sufficient autonomy, such as those who have been severely mentally handicapped from birth or early childhood. The second route is that commonly adopted in the case of children, where autonomous decisions are exercised by proxy on the child's behalf. The normally acceptable proxies are the parents (and there is argument as to whether they should exercise their proxy autonomy in the child's best interests or merely in the child's interests). The assumption that the parents are the appropriate proxies is however defeasible, certainly when there is reason to believe that they are unjustifiably acting against their child's interests and arguably even if they failing to act in their child's best interests (3). What reasons are there to reject such an approach to proxy consent in the case of sterilisation of severely mentally handicapped people?

Three arguments are plausible candidates. The first is that it can never be in a mentally handicapped person's interests, let alone in his or her best interests, to be sterilised. The second is that it violates the rights of a mentally handicapped person to sterilise him or her without the person's understanding and autonomous consent. The third is that it is against the interests of society to permit it, either because of anticipated harm and/or because of some other anticipated injustice to others.

So far as the first argument is concerned it is hard to see why it can never be in the best interests of a severely mentally handicapped person to be sterilised if it is accepted that it can sometimes be in the best interests of a mentally normal woman to be sterilised. The main benefit in the normal case is usually the virtually certain avoidance of pregnancy. Now of course there is a widespread countervailing presumption that pregnancy is a good thing. Doubtless this presumption is based on the evident truths that for many women pregnancy and the consequent nurturing of children are goods, fundamental to their flourishing, and moreover that the undergoing of pregnancy by at least some women is a necessary condition of the continued flourishing of humankind. But neither of those truths is sufficient for a conclusion that it is never in the best interests of a normal woman to be sterilised. If, as is widely accepted, it may for some women, whose beliefs permit such a choice, be beneficial, in their best interests and morally acceptable to be sterilised, why may not the same be true of some severely mentally handicapped women?

It could hardly be argued that the benefits of pregnancy justify such a ban for it is widely accepted even by those who absolutely oppose sterilisation of severely mentally handicapped women that great care should be taken to try to ensure that such women do not become pregnant. Nor can the argument that women flourish through the rearing and nurturing of their children be applied in such cases for almost 
inevitably severely mentally handicapped mothers will be unable to rear and nurture their children who will therefore be taken from them and placed elsewhere.

If the question of such women's best interests is pursued it becomes less and less clear that sterilisation is necessarily against their best interests. Given for example the pervasive assumption that pregnancy must if at all possible be avoided, women in such circumstances are likely to be subjected to considerably more repressive control over their contacts with men, and especially mentally handicapped men, in the hospitals, hostels and day centres where severely mentally handicapped people often spend much of their time. Indeed, only total sexual segregation can guarantee the avoidance of pregnancy. On the other hand if the possibility of pregnancy is eliminated by some effective means of contraception then ordinary mixed social intercourse becomes a much easier option.

Here people divide about the desirability of any form of contraception for the severely mentally handicapped. But suppose it is accepted that (a) ordinary social life, including the mixing of the sexes, is desirable for severely mentally handicapped too, and (b) that in the nature of mixed sex social life it is impossible to eliminate the possibility that sexually developed members of such a group will from time to time have sexual intercourse (some would argue that provided such intercourse was mutually desired and not exploitative it should not be prevented (4)) and (c) that it is important to ensure that no pregnancy results from any such intercourse, then the desirability of some form of effective contraception follows. However, even if contraception is accepted as desirable it may still be argued that other reversible and less dangerous forms of contraception are preferable to sterilisation which is usually irreversible and involves a surgical operation.

So far as the irreversibility is concerned this only seems to be important if there is some realistic chance that the severely mentally handicapped person will develop sufficiently to become capable of parenting and being allowed to parent a child. For it is surely the denial of possible parenthood and of the fulfilment that accompanies it which underlies such concern about the irreversibility of sterilisation. Where there is some realistic chance of such development then it does indeed seem in the best interests of the woman not to have an irreversible sterilisation. However, in many cases no such realistic chance of maturation to a state compatible with parenthood exists - and then the irreversibility of the operation seems to be irrelevant.

Undoubtedly other methods of contraception exist. Condoms and pills would probably be unsuitable for severely mentally handicapped people but intrauterine devices and long-acting injectable contraceptives could be suitable alternatives. Both, however, carry their own risks of harms (for example abdominal cramps, contraceptive failure, ectopic pregnancy, heavy and or irregular vaginal bleeding) and in particular cases may be unacceptable. Certainly sterilisation involves a surgical operation and probably a general anaesthetic but such risks are regularly taken by the mentally normal in their own interests - again it is difficult to see how acceptance of such risks in preference to those of other methods of contraception could never be in the best interests of a mentally handicapped person.

The second type of argument favouring an absolute ban on sterilisation of severely mentally handicapped people is that it transgresses their rights. Such arguments must be taken very seriously but also need careful dissection. Precisely which rights are being protected? Proferred candidates seem to be a right to reproduce, a right not to be stopped from reproducing a right to have sexual intercourse, a right not to be stopped from having sexual intercourse with a willing partner, and a right not to be surgically assaulted. The normal case again allows us to see these more clearly. Obviously there is no general right to reproduce - but there is a general prima facie right not to be stopped from reproducing and certainly in the normal case sterilisation without the person's understanding consent would be considered an outrageous transgression of his or her right not to be stopped from reproducing and his or her right not to be surgically assaulted. But again in the normal case these rights can be waived when it is in the interests of the person to waive them. One might even say that in the normal case people have a right to waive these rights.

As indicated above, we generally accept that where autonomous consent is unavailable (as is the case with severely mentally handicapped people) then the righ not to have surgical intervention without consent can in some cases properly be waived, proxy autonomous consent for surgery be justifiably given and the surgery properly considered not to be an assault. So far as the right not to be stopped from reproduction is concerned we have seen that this is in general denied to severely mentally handicapped people; if this right were to justify a ban on sterilisation then it would equally require us not to prevent in other ways severely mentally handicapped people from reproducing. So far as the right not to be stopped from having sexual intercourse is concerned, sterilisation in no way infringes any such right, as the normal case makes clear. On the contrary reliable contraception makes its implementation easier, though there are few apart from those actually working on behalf of mentally handicapped people who show any concern to accommodate their sexual desires and the law while complicated tends to diminish any such sexual rights (though it by no means excludes them (4)).

Thus no absolute rights of the severely mentally handicapped are recognised either not to have surgery without consent or to be allowed to reproduce, and any right to have sexual intercourse would not be transgressed by sterilisation (on the contrary). Thus these rights-based arguments do not seem to justify an absolute ban on the possibility of proxy consent to sterilisation of a severely mentally handicapped 
person. The criterion for such consent would still have to be agreed - the weakest acceptable criterion presumably being that the action would not be against the person's interests, the next strongest being that it would be in his or her interests, and the strongest of all being that it would be in his or her best interests. Even with the last and strongest of these criteria (itself open to major objection for excluding any consideration of the interests of others) there seems no reason to assume that sterilisation could never be in such a person's best interests.

The third argument against sterilisation of a severely mentally handicapped person is that it would be against the interests of society to permit it, either because of harm to others or because of some other injustice to society or its members. In this context we have the appalling example of Hitler's reich in which mass sterilisation of the mentally incompetent was commonplace, by a variety of disgusting methods (5), and which is one of 'the ghosts that haunt the Jeanette file' (6). Certainly if there were reason to believe that permitting of sterilisation in the interests of a mentally handicapped person would lead to the crimes of the third reich that would justify laws to ban it absolutely. This argument is an instance of the slippery slope argument, of which there are two types, the logical and the empirical. There is no logical slippery slope here if, unlike the case of the third reich, it is ensured that sterilisation is only permitted when it is not against the interests of the individual concerned (with mechanisms established to defend those interests). The problem with the second sort of slippery slope argument, the empirical, is that it can be used against any proposal that is capable of misuse. Of course if there were any realistic probability that sterilisation of the severely mentally handicapped when this was not against their own interests would lead to harm to others in society, let alone to the sort of repugnant society that characterised the third reich, then it should be prohibited. But there seems no reason to predict such developments if each case of proposed sterilisation of a mentally handicapped person is (a) not against the person's interests (and it might be safer to specify that it must be positively in his or her interests) and (b) decided in a way which explicitly protects that person's interests.

Given the worries involved, and given the peculiar vulnerability of the mentally handicapped, and given also the obvious conflicts between self-interest and the interests of the mentally handicapped which carers, parents and health care professionals alike, are likely to face, and given the irreversibility of sterilisation, it does seem wise to introduce a procedure for approval of proposed sterilisations which can be seen to defend the interests of the mentally handicapped person. One such procedure would be for all cases to obtain the approval of a court. Another might be to set up a committee to approve such proposals, of people with different backgrounds and independent of the mentally handicapped person's care, who would provide a backstop for protecting his or her interests, a system somewhat analagous to the approval now required under the Mental Health Act for certain sorts of irreversible treatments such as psychosurgery (7).

Our attitudes to proposals for the sterilisation of mentally handicapped people are subject to powerful emotions - emotions that influence our responses to sexuality in general, emotions that influence our responses to mental handicap in general, and emotions that are heightened by our attitudes to a society whose morality functions as a dread warning of the depths to which human behaviour can sink. In such circumstances we must be even more than usually meticulous about subjecting our 'gut responses' to the searchlight of critical moral reasoning.

\section{References}

(1) Brahams D. Medicine and the law. Lancet 1987; i: 757-758.

(2) Mason J K, McCall Smith R A. Law and medical ethics. London: Butterworths, 1983, 48.

(3) Kennedy I, Dworkin G. Children and the law. In: Nicholson R H, ed. Medical research with children: ethics, law and practice. Oxford, New York, Tokyo: Oxford University Press, 1986, 125-139.

(4) Dixon H, Gunn M. Sex and the law - a brief guide for staff working in the mental handicap field (England and Wales only). London: Family Planning Association Education Unit, 1985.

(5) Ivy A C. Nazi war crimes of a medical nature. In: Reiser $\mathrm{S} \mathrm{J}$, Dyck A J, Curran W J. Ethics in medicine - historical perspectives and contemporary concerns. Cambridge Mass, London: MIT press, 1977: 267-272.

(6) Acherson N. Ghosts that haunt the Jeanette file. The Observer 1987 Mar $22: 9$.

(7) Mental Health Act, 1983, s 57,58, and regulations. 